\title{
Surgical Outcomes of Revision Myringoplasty
}

\author{
Ismail Alhiraki, MD*
}

ENT Department, Al Mouwasat University Hospital, Damascus, Syria

*Corresponding author: Ismail Alhiraki, MD, PhD Candidate in Middle Ear Surgery, ENT Department, Al Mouwasat University Hospital, Damascus, Syria, Tel: +963955354314

\begin{abstract}
Objective: To evaluate the success rate of revision myringoplasty using temporalis fascia graft myringoplasty and to analyse the effect of potential influencing factors on closure of tympanic membrane (TM) and hearing outcome such as size of perforation (less or greater than $50 \%$ of tympanic membrane), site (anteriorly or posteriorly located) of perforation, whether the patient smokes or not, and condition of contralateral ear.
\end{abstract}

Materials and methods: Thirty patients were included in this prospective study, who underwent revision myringoplasty for chronic otitis media without cholesteatoma in the period between 1-1-2017/1-6-2019 in ENT H\&N surgery department in Almowasat University Hospital. Data of all patients: Perforation size and localization, middle ear status, surgical approach, graft material, pre- and postoperative morphological (otomicroscopy) and functional (hearing examination evaluating pure-tone audiogram) results were analysed. All operations were performed using an underlay technique and the retroauricular approach. The temporal fascia, were used for the reconstruction of TM. The interrelation between multiple preoperative parameters and post-operative morphological (closure of the perforation) and functional (hearing level) outcomes was analysed.

Results: Successful closure rate of the TM perforation was $86.66 \%$ (in 26 out of 30 patients) and failure rate was $13.33 \%$ (in 4 out of 30 patients) in revision myringoplasty. Graft uptake was higher in cases with small perforation (< $50 \%$ of TM) $91.30 \%$ than in cases with large perforation (> $50 \%$ of TM) $71.42 \%$, (P 0.002- statistically significant). Graft uptake with normal opposite ear was $90.90 \%$, and with abnormal opposite ear (retraction tympanic membrane without cholesteatoma) was $75 \%$ (P 0.001 - statistically significant). We found no statistically significant difference in graft uptake results with other factors. The improvement of the air bone gap between $10-20$ was $76.66 \%$ decibels ( 23 out of 30 patients) while the air bone gap (between 20-30 decibels) remained unchanged $23.33 \%$ ( 7 out of 30 patients).
Conclusion: Revision myringoplasty can offer reasonably good chances for postoperative graft healing and hearing improvement with a high success rate. This gives the patient a good benefit in protecting the ear from developing complications that may have poor structural changes in the middle ear (ossicular necrosis and tympanoscerosis) which in turn leads to hearing loss.

\section{Keywords}

Revision myringoplasty, Temporalis fascia, Tympanic membrane perforation, Revision surgery

\section{Introduction}

Myringoplasty is performed as a single procedure, or as a part of another ear operation such as a tympanoplasty or tympanomastoid surgery, is not always successful, many studies are cited to be from $75-100 \%$ $[1,2]$. The primary outcome measure for success is the perforation closure. The secondary outcomes are hearing change and reduction in frequency of ear infections. Successful results of tympanoplasty are consistent today, however, failures happen. The success rate of revision tympanoplasty for chronic otitis without cholesteatoma is not uniformly evaluated in literature. Although morphological results for primary and revision myringoplasty are similar $[3,4]$. Revision myringoplasty has been shown by numerous authors to be a risk factor for a subsequent failure in graft acceptance and hearing results $[1,5]$, consequently it has led to the need for a particular graft.

Temporalis fascia is still considered the best choice as a graft material for TM closure and it remains the most commonly used graft in primary tympanoplasties [6-8]. However, a sceptical view exists regarding the use of fascia for residual defects after primary surgery,

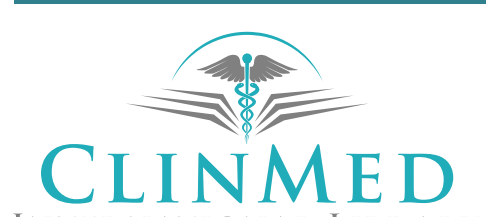

INTERNATIONAL LIBRARY

Citation: Alhiraki I (2021) Surgical Outcomes of Revision Myringoplasty. J Otolaryngol Rhinol 7:103. doi.org/10.23937/2572-4193.1510103

Accepted: June 03, 2021: Published: June 05, 2021

Copyright: (C) 2021 Alhiraki I. This is an open-access article distributed under the terms of the Creative Commons Attribution License, which permits unrestricted use, distribution, and reproduction in any medium, provided the original author and source are credited. 
although the number of studies comparing the success rates of fascia and other grafts for revision tympanoplasty is few $[9,10]$. Due to its excellent healing potential and satisfactory hearing outcomes, the cartilage has been advocated as a first choice substrate for tympanic membrane repair in revision tympanoplasty $[11,12]$. In fact, there are no studies available in which the same author reports the results of primary and revision tympanoplasty in one study using the same technique.

The limited available literature that reports the results of revision myringoplasty is sometimes used to support the contention that revision myringoplasty is less successful than primary surgery $[13,14]$. However, there are certain situations such as atelectatic ear, eustachian tube dysfunction, active suppuration, tympanosclerosis and revision myringoplasty among others, where these results have not been as gratifying. These cases are defined as high-risk perforations $[15,16]$. Candidates for revision tympanoplasty have experienced at least one failed attempt at repair of the tympanic membrane and are, therefore, at higher risk for subsequent repair failure [12,17-19]. Revision tympanoplasty cases are a delicate situation for otologists and the success rate decreases in such operations $[6,9]$.

The aim of the present study is to evaluate the success rate for revision myringoplasty after a previously unsuccessful reconstruction of TM to find the results of re-tympanoplasty using the same technique, and to analyse the effect of the factors such as size of perforation (less or greater than $50 \%$ of tympanic membrane), site (anteriorly or posteriorly located) of perforation, side of perforation, whether the patient smokes or not, and condition of contralateral ear that potentially influence the closure of TM and hearing outcome.

\section{Materials and Methods}

\section{Study design}

This prospective study was conducted in Almouwasat University Hospital during the period between 1-1-2017/1-6-2019. This study included all patients, who underwent re-myringoplasty for chronic otitis media without cholesteatoma. All patients were followed up clinically at 1 and 3 weeks postoperatively, and clinically and audiologically at 6-9 months postoperatively.

\section{Patients}

Patients who fulfilled the following criteria were included in the study: Patients between 18 and 65 years of age with residual or recurrent central tympanic perforation after previously unsuccessful reconstruction of TM and no active infection for at least 3 months before the revision procedure and those with mild (25-40 dB) conductive hearing loss. Patients below 18 years and above 65 years of age, those with active ear infection, those with attic perforation and/or retraction, those with audiometric loss not consistent with sole involvement of tympanic membrane were excluded from our study. Sex of the patient, size of perforation (less or greater than $50 \%$ of tympanic membrane), site (anteriorly or posteriorly located) of perforation, and the side of perforation, whether the patient smokes or not, condition of contralateral ear were collected to see its effect on the success rate of the surgery. Audiometric values were taken at frequencies 500,1000, 2000, and $4000 \mathrm{~Hz}$ preoperatively and at 6-9 months postoperatively.

The researchers candidated under the criteria of ethics of Damascus University which is compatible with Helsinky standards. All patients agreed to participate in the study and were well informed about the study, stages and the operation risks.

\section{Surgical techniques}

The surgery was performed under general anesthesia. The incision area behind the pinna and the auditory canal was injected by a solution of lidocaine/adrenaline 1.100.000. An incision was made $0.5-1 \mathrm{~cm}$ behind the postauricular crease with harvesting of the deep temporalis fascia graft. Thereafter, the external auditory meatus was entered, trimming the edges of tympanic membrane remnants, raising the tympanomeatal flap and annulus to reach the middle ear cavity (ossicular chain was normal in all patients) and the graft was fixed using the underlay technique, a gel foam was used to cover the graft. Repositioning of the flap was performed, followed by closure of the wound.

\section{Statistical analysis}

All of the data was collected and arranged on Excel 2016 to draw tables and illustrations, and SPSS Ver 16 was used to perform the necessary statistical tests for this work, as a t test and Chi-Square test were used, the $P$ value.

The closing of the perforation of the tympanic membrane and improvement of the air-bone gap to between 10-20 dB after 6-9 months was considered the success of this surgery.

\section{Results}

A total of 30 patients were included in the study and underwent the surgery, and completed the follow-up program. The time period from the primary operation to revision ranged from 18 months to 24 months. The patients were carried out during the preparation of the surgery, by examining the affected ear (dry central TM perforation) and the contralateral ear. We found by examining the contralateral ear preoperatively a varying degrees of retraction tympanic membrane without cholesteatoma that was evaluated by tympanometry test (type C) in 8 patients. Graft uptake was observed in 26 out of $30(86.66 \%)$. Patient's ages ranged from 18 to 65 years. There were total $12(40 \%)$ males and $18(60 \%)$ females. Fourteenth $(46.66 \%)$ underwent right myrin- 
Table 1: Factors affecting success rate of revision myringoplasty.

\begin{tabular}{|c|c|c|c|c|}
\hline Factors & Total patient & Success & Fail & $p$ value \\
\hline \multicolumn{5}{|c|}{ Site of perforation } \\
\hline Anterior & $19(63.33 \%)$ & $16(84.21 \%)$ & $3(15.78 \%)$ & \multirow[t]{2}{*}{0.513} \\
\hline Posterior & $11(36.66 \%)$ & $1(90.90 \%)$ & $1(9.09 \%)$ & \\
\hline \multicolumn{5}{|c|}{ Size of perforation } \\
\hline$>50 \%$ & $7(23.33 \%)$ & $5(71.42 \%)$ & $2(28.57 \%)$ & \multirow[t]{2}{*}{0.002} \\
\hline$<50 \%$ & $23(76.66 \%)$ & $21(87.5 \%)$ & $2(8.69 \%)$ & \\
\hline \multicolumn{5}{|c|}{ Contralateral ear } \\
\hline \multicolumn{5}{|c|}{ (Retraction/ perforation) } \\
\hline Yes & $8(26.66 \%)$ & $6(75 \%)$ & $2(25 \%)$ & \multirow[t]{2}{*}{0.001} \\
\hline No & $22(73.33 \%)$ & $20(90.90 \%)$ & $2(9.09 \%)$ & \\
\hline \multicolumn{5}{|l|}{ Smoking } \\
\hline Yes & $6(20 \%)$ & $5(83.33 \%)$ & $1(16.66 \%)$ & \multirow[t]{2}{*}{0.447} \\
\hline No & $24(80 \%)$ & $21(87.5 \%)$ & $3(12.5 \%)$ & \\
\hline
\end{tabular}

Table 2: Hearing results after revision myringoplasty.

\begin{tabular}{|l|l|l|l|}
\hline & Pre-operative & Post-operative & $\boldsymbol{P}$ value \\
\hline Bone Conduction Threshold & $16.75 \pm 5.08$ & $13.50 \pm 6.02$ & 0.332 \\
\hline Air Conduction Threshold & $38.5 \pm 15.05$ & $27.25 \pm 13.81$ & 0.001 \\
\hline Air Bone gap & $21.5 \pm 11.20$ & $13.25 \pm 7.03$ & 0.004 \\
\hline
\end{tabular}

goplasty and sixteenth (53.33\%) underwent left myringoplasty. The graft uptake results in relation to various factors are shown in tables below. Site of perforation and smoking status were not found to be significant determining factor for successful revision myringoplasty. Graft uptake was higher in cases with small perforation ( $<50 \%$ of TM) $91.30 \%$ than in cases with large perforation (> 50\% of TM) $71.42 \%$, this result was statistically significant $(p=0.002)$. We found that 22 patients, who underwent myringoplasty, had normal contralateral ear. Graft was taken up in 20 (90.90\%). 8 patients had a varying degrees of retraction of TM in the contralateral ear and graft was taken up in 6 patients (75\%). Graft uptake was significantly poor when the contralateral ear had retraction of TM $(p=0.001)$. All 30 patients had normal ossicular chain. The average pre-operative bone conduction threshold was $16.75 \mathrm{~dB}$ and the average post-operative bone conduction threshold improved to $13.50 \mathrm{~dB}$, which was not statistically significant $(P=0.332)$. The average pre-operative air conduction threshold was $38.5 \mathrm{~dB}$ and the average post-operative air conduction threshold improved to $27.25 \mathrm{~dB}$, which was statistically significant $(p=0.001)$. The average pre-operative air bone gap was $21.5 \mathrm{~dB}$ and the post-operative air bone gap was $13.25 \mathrm{~dB}$, which was statistically significant $(p=$ 0.004) Table 1 and Table 2.

\section{Discussion}

Myringoplasty is the most common middle ear surgery performed in our center, with cases referred from all regions of the country. Repair of a recurrent tympanic membrane perforation is a challenge for the ear surgeon. Although primary tympanoplasty has high successful rates, around $90 \%$ or higher $[6,7,20]$, successful outcome in revision cases can be more difficult to achieve [21,22].

There was a significant difference in graft uptake with the size of perforation in this study, similar results have been shown in some international studies. In this study the researcher achieved a success rate of $91.30 \%$ for small perforations (size less than 50\%) and $71.42 \%$ for large perforations (size greater than $50 \%$ ). Howev$\mathrm{er}$, in the case of larger TM defects, healing has a much poorer prognosis and because of the increased technical difficulty and area that must be vascularized and epithelialized with larger perforations, surgical failures are not unexpected $[23,24]$. The absence of an adequate residual TM in subtotal or total TM perforations remains a challenge to otolaryngologists. Study by Kotecha, et al. and Onal, et al. have shown better graft uptake in small size perforation as compared with large perforation [25].

In this study, the researcher found the status of the contralateral ear to be an important prognostic factor for graft uptake. Graft uptake was significantly poor when the contralateral ear had a retraction of TM $(P=$ 0.001). We found similar results in some international studies. This finding might indicate an eustachian tube dysfunction and the tendency of chronic otitis media to present as a bilateral disease [25]. The status of contralateral ear is important in two aspects: First, in its contribution for understanding the pathogenesis of otitis media, and second, in its implications in treatment and 


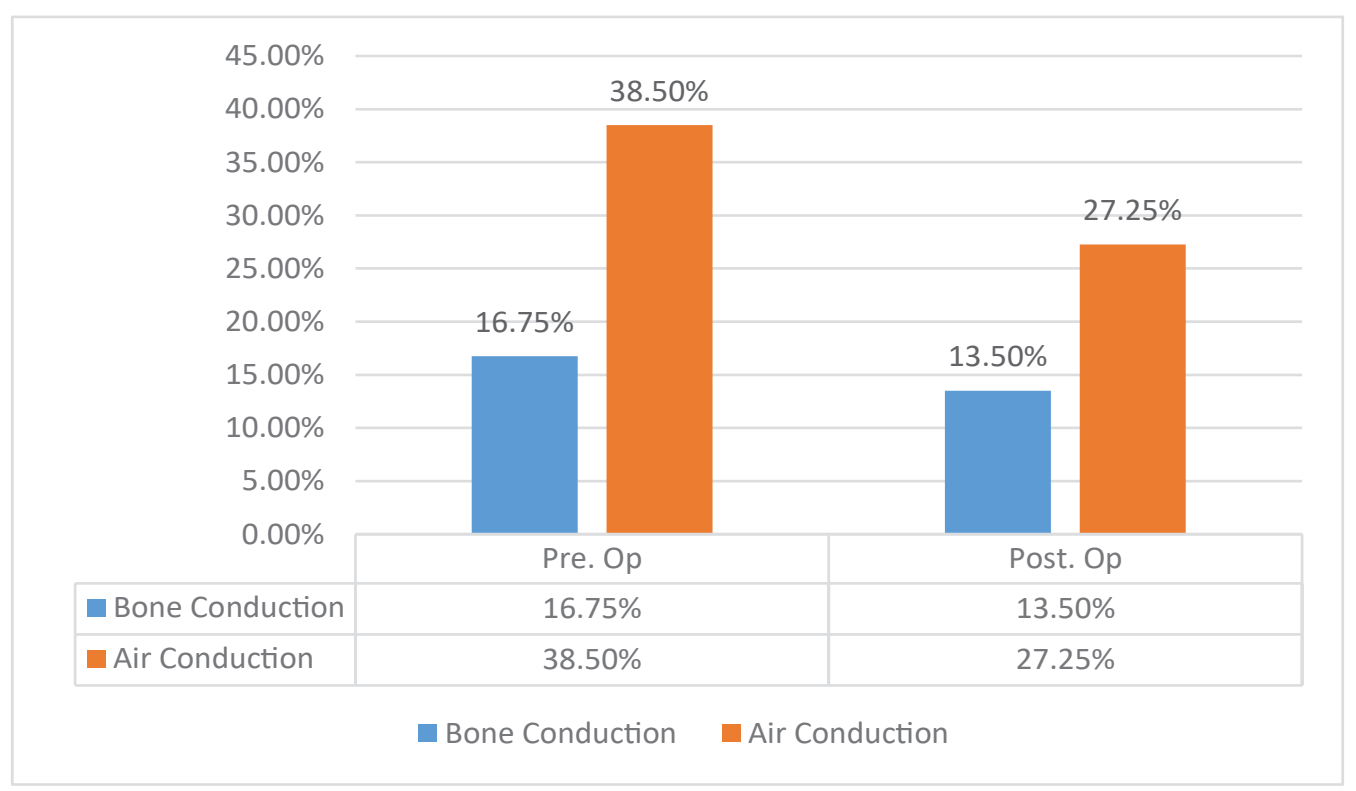

Figure 1: Shows change in air-bone thresholds before and after surgery.

counseling. The researcher found similar results in the studies by Calyan, et al. and Ophir, et al. [25,26].

There was no significant difference in graft uptake with the site of perforation in this study, although the success rate in posterior perforations was slightly higher than anterior perforations $90.90 \%$ vs. $84.21 \%$ respectively. This has been attributed to technical challenge to repair due to the poor visibility of anterior margin of perforation, more difficult access, inadequate graft support, and relatively poorer perfusion in anterior portion of tympanic membrane [25], most of the recent studies have found that the site of perforation is not a determining factor for successful myringoplasty $[27,28]$.

In this study, 24 patients were non-smokers and 6 patients were smokers. The graft uptake in non-smoking group was $87.5 \%$ and that in the smoking group was $83.33 \%$. This difference was not statistically significant, likely due to a disproportionate population within the subgroup.

However, we did not take into account details of amount and duration of smoking in this study. We have to know that smoking changes the amount and viscosity of mucous and destroys the ciliated epithelium of the eustachian tube and middle ear mucosa [28]. Nicotine causes cutaneous vasoconstriction, promotes thrombosis, and carbon monoxide inhaled in cigarette smoke also reduces the oxygen-carrying capacity of the blood, which in turn causes inadequate oxygenation of the graft. These factors may impair the graft vascularization. The systemic effects of smoking are the chemoallergic and immunosuppressive properties that may cause increased susceptibility to the infectious agents and thereby lead to graft failure [28]. A study by Wasson, et al. did not find smoking to be a significant factor for successful myringoplasty [29-31].

The researcher also found a statistically significant functional result when studying closure of the $A B G$ in our study, with most being between 10-20 dB. Hearing improvement after myringoplasty is statistically significant if the ossicles are normal.

The researcher also found that the leading causes of failure (4 cases) were associated with a complete notake of the graft (1 case), infection with graft necrosis (1 case) and poor anterior adaptation of the graft ( 2 cases).

\section{Conclusion}

Revision myringoplasty can offer reasonably good chances for postoperative graft healing and hearing improvement with a high success rate. This gives the patient a good benefit in protecting the ear from developing complications that may have poor structural changes in the middle ear (ossicular necrosis and tympanosclerosis) which in turn leads to hearing loss. Despite the recommendation of many studies that the use of a cartilage graft in the revision myringoplasty is more preferred, the researchers found that using a facial graft gives good surgical results, both in terms of graft uptake or improving hearing after surgery. In this study, we were not able to adopt a control group for comparison, and the sample was relatively small. Therefore, the researchers recommend in the future to conduct similar studies, but with the adoption of a control group to compare the results and take a larger sample in order to make the results more accurate.

\section{Acknowledgements}

Prof. M. Nabil Dandashli. MD, PhD made great contributions in editing the intellectual content and proofreading of this paper.

\section{References}

1. Kazikdas KC, Onal K, Boyraz I, Karabulut E (2007) Pali- 
sade cartilage tympanoplasty for management of subtotal perforations: A comparison with the temporalis fascia technique. Eur Arch Otorhinolaryngol 264: 985-989.

2. Ozbek C, Ciftci O, Tuna E, Yazkan O, Ozdem C (2008) A comparison of cartilage palisades and fascia in type 1 tympanoplasty in children: Anatomic and functional results. Otol Neurotol 29: 679-683.

3. Sheehy JL, Anderson RG (1980) Myringoplasty: A review of 472 cases. Ann Otol Rhinol Laryngol 89: 331-334.

4. Boone RT, Gardner EK, DornhoVer JL (2004) Success of cartilage grafting in revision tympanoplasty without mastoidectomy. Otol Neurotol 25: 678-681.

5. Dornhofer J (2003) Cartilage tympanoplasty: Indications, techniques, and outcomes in a 1000-patient series. Laryngoscope 113: 1844-1856.

6. Angeli S, Kulak L, Guzman J (2016) Lateral tympanoplasty for total or near total perforation: Prognostic factors. Laryngoscope 116: 1594-1599.

7. Djalilian HR (2006) Revision tympanoplasty using scar tissue graft. Otol Neurotol 27: 131-135.

8. Chang CY, Gray LC (2005) Pressed scar tissue for tympanic membrane grafting in revision tympanoplasty. Otolaryngol Head Neck Surg 132: 30-36.

9. Neumann A, Jahnke K (2005) Reconstruction of the tympanic membrane applying cartilage: Indications, techniques and results. HNO 53: 573-584.

10. Berger G, Ophir D, Berco E, Sade J (1997) Revision myringoplasty. J Laryngol Otol 111: 517-520.

11. Halik JJ, Smyth GD (1988) Long-term results of tympanic membrane repair. Otolaryngol Head Neck Surg 98: 162169.

12. Altuna X, Navarro JJ, Martínez Z, Lobato R, Algaba J (2010) Miringoplastia con cartílago en isla. Resultados anatómicos y funcionales de 122 casos. Acta Otorrinolaringol Esp 61: 100-105.

13. Booth JB (1974) Myringoplasty: The lessons of failure. J Laryngol Otol 88: 1223-1236.

14. Indorewala S (2002) Dimensional stability of the free fascia grafts: An animal experiment. Laryngoscope 112: 727-730.

15. Buckhingam RA (1992) Fascia and perichondrium atrophy in tympanoplasty and recurrent middle ear atectasis. Ann Otol Rhinol Laryngol 101: 755-758.

16. Utech $H$ (1959) Ueber diagnostische und therapeutische Moeglich-keiten der Tympanotomie bei Schalleitungsstoerungen. Laryngol Rhinol 38: 212-221.
17. DornhoVer JL (2003) Cartilage tympanoplasty: Indications, techniques, and outcomes in a 1,000 patient series. Laryngoscope 113: 1844-1856.

18. Heerman J (1992) Autograft tragal and conchal palisade cartilage and perichondrium in tympanomastoid reconstruction. Ear Nose Throat J 71: 344-349.

19. Amedee RG, Mann WJ, Riechelmann H (1989) Cartilage palisade tympanoplasty. Am J Otol 10: 447-450.

20. Moore GF (2002) Revision tympanoplasty utilizing fossa triangularis cartilage. Laryngoscope 112: 1543-1554.

21. Onal K, Uguz MZ, Kazikdas KC, Gursoy ST, Gokce H (2015) A multivariate analysis of otological, surgical and patient-related factors in determining success in myringoplasty. Clin Otolaryngol 30: 115-120.

22. Kotecha B, Fowler S, Topham J (1999) Myringoplasty: A prospective audit study. Clin Otolaryngol Allied Sci 24: 126129.

23. Pignataro L, Grillo Della Berta L, Capaccio P, Zaghis A (2001) Myringoplasty in children: Anatomical and functional results. J Laryngol Otol 115: 369-373.

24. Avilés Jurado FJ, Merán Gil JL, Tobed Secall M, Doménech Vadillo E, Masgoret Palau E, et al. (2009) Myringoplasty: auditory follow-up and study of prognostic factors. Acta Otorrinolaringol Esp 60: 169-175.

25. Moore GF (2012) Candidate's thesis: Revision tympanoplasty utilizing fossa triangularis cartilage. Laryngoscope 112: 1543-1554.

26. Sismanis A, Dodson K, Kyrodimos E (2018) Cartilage "shield" grafts in revision tympanoplasty. Otol Neurotol 29: 330-333.

27. Ben Gamra O, Mbarek C, Khammassi K, Methlouthi N, Ouni $\mathrm{H}$, et al. (2008) Cartilage graft in type I tympanoplasty: audiological and otological outcome. Eur Arch Otorhinolaryngol 265: 739-742.

28. Ghanem MA, Monroy A, Alizade FS, Nicolau Y, Eavey RD (2006) Butterfly cartilage graft inlay tympanoplasty for large perforations. Laryngoscope 116: 1813-1816.

29. Westerberg J, Harder H, Magnuson B, Westerberg L, Hydén D (2011) Ten year myringoplasty series: Does the cause of perforation aVect the success rate? J Laryngol Otol 125: 126-132.

30. Kessler A, Potsic WP, Marsh RR (1994) Type 1 tympanoplasty in children. Arch Otolaryngol Head Neck Surg 120: 487-490.

31. Wasson JD, Papadimitriou CE, Pau H (2009) Myringoplasty: Impact of perforation size on closure and audiological improvement. J Laryngol Otol 123: 973-977. 